Thoolen, B., Ridder, D. de, Bensing, J., Gorter, K., Rutten, G. No worries, no impact? A systematic review of emotional, cognitive, and behavioural responses to the diagnosis of type 2 diabetes. Health Psychology Review: 2008, 2(1), 65-93

\begin{tabular}{|l|l|}
\hline $\begin{array}{l}\text { Postprint } \\
\text { Version }\end{array}$ & 1.0 \\
\hline $\begin{array}{l}\text { Journal website } \\
\text { Pubmed link }\end{array}$ & $\underline{\text { http://www.informaworld.com/smpp/content } \sim \text { content=a901624558 }}$ \\
\hline DOI & $10.1080 / 17437190802311361$ \\
\hline
\end{tabular}

This is a NIVEL certified Post Print, more info at http://www.nivel.eu

\title{
No worries, no impact? A systematic review of emotional, cognitive, and behavioural responses to the diagnosis of type 2 diabetes.
}

\author{
BART THOOLEN $^{\mathrm{A} *}$, DENISE DE RIDDER ${ }^{\mathrm{A}}$, JOZIEN BENSING ${ }^{\mathrm{B}}$, KEES GORTER ${ }^{\mathrm{C}}$ AND GUY \\ RUTTEN $^{\mathrm{D}}$ \\ ${ }^{a}$ Department of Clinical and Health Psychology, Faculty of Social Sciences, Utrecht \\ University, Utrecht, The Netherlands; \\ ${ }^{b}$ NIVEL, Netherlands institute for Health Services Research, Utrecht, The Netherlands; \\ 'Julius Center for Health Sciences and Primary Care, Utrecht, The Netherlands; \\ 'University Medical Centre Utrecht, General Practice, GA utrecht, Utrecht,
}

The Netherlands Previous research suggests that patients with type 2 diabetes quickly adjust to their diagnosis, but most studies tend to focus on emotional outcomes. This systematic review also examines patients' cognitive and behavioural responses in the first year after diagnosis, based on empirical studies published between 1993 and 2008. A total of 24 studies are presented in order from most to least rigorous design. A further distinction is made between being diagnosed in the context of a screening programme and other forms of diagnoses. This review confirms that the diagnosis of type 2 diabetes has limited longterm emotional impact, if at all, regardless of how patients are detected. Examination of cognitive and behavioural responses indicate that most patients underestimate the seriousness of their diabetes, overestimate their ability to control it and show limited engagement in the management of their disease. The results also indicate considerable variations in adjustment to the illness. These are related to symptom experience, prior knowledge, and information provision and treatment. Overall, this review shows that a lack of emotional distress does not necessarily indicate a successful adjustment but may instead reflect patients’ tendency to avoid dealing with and managing their diabetes until the first signs and symptoms appear, potentially undermining the effectiveness of early detection and treatment.

\section{INTRODUCTION}

Being diagnosed with a chronic illness can have a profound impact on one's life and generally requires considerable psychological adjustment in order to cope with the new situation. For some chronic diseases (e.g., cancer, rheumatoid arthritis), coping is primarily geared to dealing with the direct threat to one's health in the form of pain and other progressive and debilitating symptoms. For other diseases, symptoms may be less apparent, 
Thoolen, B., Ridder, D. de, Bensing, J., Gorter, K., Rutten, G. No worries, no impact? A systematic review of emotional, cognitive, and behavioural responses to the diagnosis of type 2 diabetes. Health Psychology Review: 2008, 2(1), 65-93

but patients can be confronted with strict treatment regimens which require them to make considerable changes in their lifestyle if they wish to keep their illness under control (De Ridder, Geenen, Kuijer, \& Middendorp, in press). These latter diseases present patients with a so-called self-regulatory dilemma in which they must make considerable changes in the short term to avoid long-term threats (Carver \& Scheier, 1998).

Type 2 diabetes is perhaps the quintessential of this latter category of chronic diseases. Characterised by chronically elevated blood sugar levels, type 2 diabetes generally begins with minimal symptoms, but when left untreated, the disease is associated with severe vascular complications such as cardiovascular disease, blindness, foot amputation and kidney failure. While actual manifestation of these complications may take years, the newly diagnosed patient is often immediately confronted with a variety of medical treatments and lifestyle changes geared to normalising blood sugar levels and decreasing cardiovascular risk. The success of the treatment relies heavily on the patient's ability to manage the illness on a daily basis for the rest of his or her life, a difficult task which can have considerable impact on one's partner, family, work and social life (Glasgow \& Eakin, 1998).

Understanding how newly diagnosed patients adjust to living with such an asymptomatic but demanding condition is important, and should help professionals to adequately support this group of patients. From a theoretical stand point, type 2 diabetes is an interesting example of a condition which places a premium on one's ability for selfregulation (De Ridder \& DeWit, 2006). Parallels can be drawn with the study of preventive behaviours (De Wit \& Stroebe, 2004) which highlight the importance of motivational processes and social influences in engendering intentions to change when confronted with a potential future health threat. In diabetes, however, the sheer number and complexity of preventive behaviours can make self-care a particularly daunting task, and even the most motivated patients often fail to change their lifestyle and maintain new behaviours over any length of time (Glasgow \& Eakin, 1998). Motivation and will-power are important, but many failures in self-care occur because people often fail to take into account the many barriers and situations which can undermine their behaviours (De Ridder \& De Wit, 2006).

This highlights the difficulty of translating intentions into sustained behaviours, and indicates the importance of looking beyond patients' intentions to examine the strategies which they employ in order to meet their goals (Gollwitzer, 1999; Webb \& Sheeran, 2006). Type 2 diabetes also exemplifies the trade-off between short and very long term goals, between continuing one's present lifestyle versus changing behaviours to avoid a vague and long-term threat. From this perspective, parallels can be drawn with studies on futureoriented thinking and coping (e.g., Aspinwall, 2005; Chapman, 2003) which highlight the difficulties in appreciating and dealing with long-term threats to one's health. Finally, beliefs about the severe complications and rigorous lifestyle change which diabetes is associated with could understandably make receiving the diagnosis a highly distressing event, influencing subsequent coping strategies to either undermine or support self care (Cameron \& Leventhal, 2003).

This systematic review examines how recently diagnosed patients adjust to living with type 2 diabetes during the early stages of their disease. The focus on newly diagnosed patients is particularly relevant given the recent and dramatic increase in the prevalence of diabetes, with more than 200 million patients worldwide (Wild, Roglic, Green, Sicree, \& King, 2004; Zimmet, Alberti, \& Shaw, 2001). This increase is in part due to ageing populations and increasingly sedentary lifestyles, but more proactive case finding and screening programmes among at-risk populations have also played an important role. Such programmes recognise that a large number of patients remain undiagnosed, untreated and unaware of their illness, and assume that an early detection and treatment will help to prevent or at least delay the onset of long-term complications (Engelgau, Venkat Narayan, \& Herman, 2000). However, the success of such programmes ultimately depends on the patients' ability to accept their diagnosis and engage in their self-care. 
Thoolen, B., Ridder, D. de, Bensing, J., Gorter, K., Rutten, G. No worries, no impact? A systematic review of emotional, cognitive, and behavioural responses to the diagnosis of type 2 diabetes. Health Psychology Review: 2008, 2(1), 65-93

Up till now, most research suggests that newly diagnosed patients adjust relatively quickly to their diagnosis. From a large number of studies across a wide range of illnesses we know that patients can experience their diagnosis as a time of personal crisis and emotional upheaval, but this period of upheaval is usually relatively short, with most patients adapting to their illness within a few months (Sidell, 1997; Stanton, Collins, \& Sworowski, 2001). Furthermore, positive emotions such as relief and affirmation are not unusual (Cassileth, et al., 1984). One could conceive that being diagnosed in asymptomatic conditions such as type 2 diabetes could be especially distressing, particularly in a screening programme, because patients do not feel ill and are therefore not expecting the diagnosis (Doust, Mannes, Bastian, \& Edwards, 2003). However, an extensive review across a wide range of illnesses found that being diagnosed during a screening is generally only associated with a brief period of distress, if at all (Shaw, Abrams, \& Marteau, 1999).

Similarly, a recent review on screening for type 2 diabetes also found that neither the screening procedure nor the diagnosis had any effect on patients' distress or well-being in the year following the initial diagnosis (Adriaanse \& Snoek, 2006). This finding goes against much of the literature which often describes the adjustment to chronic illness as a long-term process of bereavement in which patients have to go through a series of emotional stages in accepting and integrating their illness (Lorig, et al., 2000).

However, a lack of emotional distress does not imply that patients have come to terms with their illness. First, lack of emotional distress could also reflect an inhibition or denial of negative emotions, which may be useful when initially receiving the diagnosis, but may hamper health-seeking behaviours and self-management when these emotions remain unresolved (Wiebe \& Korbel, 2003). Second, the clinical measures of anxiety and depression which most studies rely on may not be sensitive to the many concerns and worries which newly diagnosed patients are likely to experience (Polonsky, 2000).

Furthermore, psychological adjustment does not only entail the regulation of emotions. Adjusting to a chronic illness such as type 2 diabetes poses a dilemma which also requires considerable cognitive and behavioural effort (Cameron \& Leventhal, 2003). With regard to cognitions, patients associate different diseases with different levels of threat and controllability, and this has been found to influence their emotional reactions during the course of their illness (Fournier, de Ridder, \& Bensing, 2002; Heszen-Niejodek, Gottschalk, \& Januszek, 1999). In addition, the majority of behavioural change theories also consider such cognitions to be decisive factors in the realisation of health goals (Connor \& Norman, 2005): i.e., patients must accept the reality of the health threat, recognise the need for behavioural change and feel able to set goals and make plans to achieve these changes. From this perspective, the asymptomatic nature of diabetes can make it more easy to downplay the seriousness of the condition. On the other hand, it is a relatively controllable disease which could make patients more confident in adapting to and managing their illness. Finally, while behavioural adjustment is necessary to keep the disease under control, most studies on diabetes repeatedly found that a significant proportion of patients fails to engage in adequate self-management (Peyrot, et al., 2005), making it questionable whether mild emotional reactions do in fact reflect successful adjustment.

In spite of this, the majority of studies on newly diagnosed diabetes primarily focused on patients' emotional outcomes, and, in particular, on patients' well-being, and anxiety or distress following diagnosis. Less attention has been given to the worries, concerns and perceptions which newly diagnosed patients associate with their illness or its treatment, let alone how they manage their illness in the first year after diagnosis. The goal of this review is therefore to critically assess recent empirical evidence regarding the emotional, cognitive and behavioural responses of patients newly diagnosed with type 2 diabetes.

In addition, this study also examines potential variations in patients' psychological adjustment, and in particular, it focuses on factors surrounding the diagnosis which could influence patients' subsequent reactions. The most obvious factor is the potential effect which screening has on subsequent adjustment. As stated before, relevant studies generally 
Thoolen, B., Ridder, D. de, Bensing, J., Gorter, K., Rutten, G. No worries, no impact? A systematic review of emotional, cognitive, and behavioural responses to the diagnosis of type 2 diabetes. Health Psychology Review: 2008, 2(1), 65-93

find that screening has limited impact on emotional outcomes, but the effect on cognitive and behavioural outcomes is less clear. It can be assumed that a diagnosis by screening is unexpected as patients are unaware of their illness up to that point. On the one hand, this could be because these patients either do not have relevant symptoms or do not experience them as such. On the other hand, these patients may not have prior knowledge or experience with the disease, and may therefore be less familiar with the signs and consequences of the disease. This may affect their subsequent cognitive and behavioural adjustment if not their emotions: Cognitive appraisals of a health threat have been found to depend on one's knowledge and past experience with illness (Weinstein, 1989) and one's comparisons with other patients (Taylor \& Lobel, 1989), but also on the unexpectedness of and manner in which information about the health threat is conveyed (Renner, 2004; Rothman \& Salovey, 1997). Given the above discussion, we deem it important to take a closer look at studies on screening and diagnosis of diabetes, before concluding that a diagnosis of diabetes, in a screening programme or otherwise, has only limited impact.

\section{METHODS}

This review is based on recent literature, published in English from 1993 to 2008, and listed in the Psych-info, Medline, Cochrane and CINAHL databases. We restricted our search to this period given the recent epidemic growth in the prevalence of diabetes and the increasing research and public awareness on diabetes in the last 15 years. Search terms included emotional, cognitive and behavioural terms, focusing on patients with type 2 diabetes and their outcomes in the first year after diagnosis. The results of this are described in Table 1. Initial selection of studies was based on the information given in the abstract. Studies which did not focus on newly diagnosed patients, but clearly examined their reaction to diagnosis and/or adjustment in the first year were also included for further perusal. We included prospective, cross-sectional, and retrospective studies, designs with and without control groups, and data collection involving either questionnaires, interviews, or focus groups. We preferred studies with a robust design, but included studies with a more narrative or weaker design as these often give more insight into the content of patients' emotional, cognitive and behavioural outcomes.

\section{[TABLE 1]}

Subsequently, studies identified in our search were reviewed by two of the present authors. Overall, few studies focused on recently diagnosed patients or took account of time since the initial diagnosis. In addition, the majority of studies were excluded due to their exclusive focus on biomedical parameters. Other exclusion criteria were an inadequate description of study populations, designs or results, non-empirical studies (e.g., reports, advice or opinions), and studies in which patients had already received some form of psychological intervention. Based on this last criterion, the majority of studies using focus groups were excluded as these took place within a diabetes educational setting. The initial selection was lenient, and when in doubt, the full texts were collected or contact was made with the authors. The net result was 24 studies (described in 31 empirical articles) studying the impact of and adjustment to a diagnosis of type 2 diabetes.

\section{EVALUATION OF INDIVIDUAL STUDIES}

In evaluating the strength of the studies we followed the system developed by the National Heart, Lung and Blood institute (NHLB), categorising studies based on their ability to allow for casual inferences (cf. Faith, Fontane, Baskin, \& Allison, 2007). This system differentiates between randomised controlled trials with rich (category 1 ) versus limited body of data (category 2), non-randomised trials and observational (cross-sectional) studies (category 3) and focus groups (category 4). The strength of empirical evidence is assessed based on the 
Thoolen, B., Ridder, D. de, Bensing, J., Gorter, K., Rutten, G. No worries, no impact? A systematic review of emotional, cognitive, and behavioural responses to the diagnosis of type 2 diabetes. Health Psychology Review: 2008, 2(1), 65-93

number of studies falling into each category. The present selection, described in Table 2, included four category 2 studies, 18 category 3 studies, and two category 4 studies, but no large-scale randomised trials (category 1). Seven studies were prospective, but only four of these compared newly diagnosed patients with other groups and could be considered to fall in the second category. The other three thus fell in the third category. Fifteen studies were observational, using questionnaires or interviews to assess patients at a single time point (category 3). Of these, eight focused on patients diagnosed for less than one year while six were retrospective, requiring respondents to reflect on experiences many months and up to 30 years in their past. Two studies used focus groups and therefore fell into the fourth category. The sample size in most studies was limited (five studies had less than 20 participants, eight had between 20 and 100 participants while 11 studies had more than 100). We have taken these limitations into account, following the NHLB in presenting studies with respect to their ability to allow for causal inferences on patients' emotional, cognitive, and behavioural responses. The choice for this system of analysis over a meta-analysis was based on two points. First, the poor quality and heterogenity of studies did not allow for the calculation of effect sizes needed in a meta-analysis. But second, we also believed the system of the NHLB, with its allowance for more descriptive studies, to add depth to the review, giving meaning to the more robust quantitative studies, and thereby helping to generate hypotheses. Studies will be presented from the most to the least rigorous design (prospective, observational or focus group). In addition, we also differentiate between studies involving patients diagnosed less than one year and those retrospectively assessing patients' adjustment at a later stage. We first evaluate the state of evidence for each outcome separately, underlining important strengths and limitations of the available evidence, and then attempt to integrate the findings on patients' emotional, cognitive, and behavioural adjustment. Finally, we examine the selected studies for evidence of factors which influence patients' adjustment, also taking the aforementioned criteria into account.

\section{[TABLE 2]}

\section{RESULTS}

\section{Emotional responses}

Sixteen of the 24 studies investigated emotional responses of patients recently diagnosed with type 2 diabetes (see Table 2). The studies with the most rigorous design were those investigating emotional reactions to screening. Given this distinction between screening and other diagnoses we have chosen to take this into account when presenting patients' outcomes. In addition, we have also reviewed studies to assess the content of their worries and concerns.

\section{Screen-detected patients}

Five studies examined emotional outcomes in screen-detected patients. Three had prospective controlled designs (category 2), two were cross-sectional studies (category 3). In a prospective controlled trial examining the impact of a screening programme, newly detected patients $(\mathrm{n}=150)$ were compared with other screening attendees and nonattendees (Eborall et al., 2007b), including validated measures of (state-) anxiety and depression taken from screening up till 15 months later. Overall, the screening procedure had little impact on emotional outcomes when attendees and non-attendees were compared, but immediately after screening, newly diagnosed participants reported higher state anxiety and depression than those who screened negative. These differences were small and clinically irrelevant, however, and had disappeared at the $3=6$ months and 12=15 months follow-up. Furthermore, interviews with a small subsample $(n=8)$ revealed that only one participant reported shock at diagnosis. 
Thoolen, B., Ridder, D. de, Bensing, J., Gorter, K., Rutten, G. No worries, no impact? A systematic review of emotional, cognitive, and behavioural responses to the diagnosis of type 2 diabetes. Health Psychology Review: 2008, 2(1), 65-93

In a series of prospective studies, Adriaanse and associates examined the psychological consequences of screening in terms of emotional adjustment, well-being and perceived mental health, from before diagnosis to 12 months after diagnosis, comparing screendetected patients $(\mathrm{n}=116)$ with non-diabetics, at-risk patients and patients diagnosed via the general practice (Adriaanse et al., 2003, 2004a,b; Adriaanse, Snoek, Dekker, van der Ploeg, \& Heine, 2002; Snoek et al., 2005). They found that participants evaluated the screening process very positively. Moreover results did not indicate any lasting anxiety, regardless of the result of the screening process. The vast majority showed continued healthy outcomes (e.g., well-being and perceived mental health) two weeks to one year after diagnosis, with scores comparable to non-diabetics and patients at-risk for diabetes, and significantly better than those diagnosed in the general practice. In interviews with a subsample of 20 screendetected patients, 19 reported some surprise at diagnosis but only one reported negative feelings (Adriaanse et al., 2002).

In another prospective study, a screening trial among 1253 veteran outpatients found that a positive diagnosis had no negative effects on well-being or perceived health 12 months later when diabetic and non-diabetic patients were compared (Edelman, Olsen, Dudley, Harris, \& Oddone, 2002). This study was limited to male outpatients, of which $95 \%$ had comorbidities, which could diminish differences between diabetic and nondiabetic patients.

Two observational studies also examined screening related outcomes. Skinner and colleagues (2006a, 2006b) examined the impact of the screening programme itself, and found that participants $(n=1189)$ reported little anxiety at screening. However, measurements took place before patients received their results and therefore did not indicate how they ultimately responded to their diagnosis. Finally, another survey study among 196 screendetected patients diagnosed $3=33$ months previously found that most patients reported low anxiety, depression and diabetes related distress, regardless of the time since diagnosis (Thoolen, De Ridder, Bensing, Gorter, \& Rutten, 2006). Overall, these studies confirm that screening has no long-term emotional effects for most patients, and only limited short-term effects.

\section{Other newly diagnosed}

Eleven studies examined emotional outcomes of patients regardless of the manner of diagnosis, and included two category 2 studies, eight category 3 studies and one category 4 study. Four studies had a prospective design, focusing on changes in the first year after diagnosis,. Adriaanse and associates (2004a) found that patients diagnosed in the general practice $(n=49)$ reported significantly lower well-being and perceived health, and more symptom distress than screen-detected patients $(n=116)$ at diagnosis. However, to put this into perspective, mental health was relatively high in both groups, while those diagnosed in the general practice improved significantly in terms of symptom distress and well-being in the subsequent year.

Nichols and Brown (2004) identified new patients from their medical records and compared those who had $(\mathrm{n}=105)$ and had not $(\mathrm{n}=168)$ received a diagnosis from their general practitioner with healthy controls ( $\mathrm{n}=589$ ), examining health related quality of life over 12 months. Patients had significantly poorer physical health, but similar mental health in comparison to healthy controls at baseline. There were no significant changes in the subsequent year, regardless of whether or not patients received a positive diagnosis. There was considerable variation with one-third of patients reporting poor mental health.

In a series of repeated interviews Lawson and associates investigated changes in emotional responses to diabetes from diagnosis to six months, one year and two years later $(\mathrm{n}=158)$. Overall, scores on the measures were not high to start out with and decreased significantly over the two year period (Lawson, Bundy, \& Harvey, 2007Lawson, Bundy, \& Harvey, 2008). 
Thoolen, B., Ridder, D. de, Bensing, J., Gorter, K., Rutten, G. No worries, no impact? A systematic review of emotional, cognitive, and behavioural responses to the diagnosis of type 2 diabetes. Health Psychology Review: 2008, 2(1), 65-93

Emotional adjustment in the first year was also assessed by a series of repeated interviews with 40 patients newly diagnosed with type 2 diabetes (Peel, Parry, Douglas, \& Lawton, 2004). This study found considerable variations in patients' responses, but strong emotional reactions to diagnosis were rare. While asymptomatic patients tended to experience more shock and denial, most patients overcame these negative emotions within a few weeks. The other seven studies were observational. These studies suggest that there is considerable variation in patients' emotional response to diagnosis. One study examined the emotional adjustment of 71 patients two weeks after diagnosis, finding that half reported negative emotions, while one-quarter of the 71 also felt unable to cope (Pibernik- Okanovic, Roglic, Prasek, \& Metelko, 1996). Those with the most negative outcomes were found to have the poorest metabolic control, indicating a link between physical and emotional outcomes. Two other studies among patients diagnosed less than one year previously also report substantial variations in emotional responses but failed to indicate the number of patients actually experiencing distress (Everett \& Kerr, 1998; Richards \& Morris, 2001).

The remaining four studies were retrospective, asking patients to reflect on their diagnosis up to 30 years after the initial diagnosis. Overall, results indicate that patients experience a wide range of emotions at diagnosis, including shock, anxiety, denial, anger, fear, and loss of control on the one hand, and relief and affirmation on the other (Dietrich, 1996; Gillibrand \& Flynn, 2001). The two studies indicating the number of patients to report various emotions found that between one-quarter and one-half experience strong negative emotions at diagnosis (Beeney, Bakry, \& Dunn, 1996; Lo \& Maclean, 2001).

\section{Worries and concerns: content}

That patients do not score high on measures of emotional distress does not mean that they have no worries or concerns. Nine studies investigated the content of patients' worries and concerns (eight category 3, one category 4).

The only study on screen-detected patients found that most patients reported no major worries or concerns, although $60 \%$ were somewhat worried about the implications of dieting, as this often entailed major adjustments in their lifestyles (Adriaanse et al., 2002) Two studies assessed the concerns of patients by questionnaires regardless of type of diagnosis (Beeney et al., 1996; Woodcock \& Kinmonth, 2001). Woodcock and Kinmonth (2001) assessed the concerns of 250 type 2 patients one year after diagnosis. In an open question, 'following dietary advice' was cited most often, followed by 'fears of declining health'. Beeney and associates (1996) retrospectively assessed concerns at diagnosis in 1159 diabetes patients (of which 785 type 2) diagnosed an average 10 years before the study took place, and found that $20 \%$ of patients reported no concerns at all. The concerns reported most often were diet (21\%), followed by injections (15\%), complications (13\%) and lifestyle impact (13\%). Both studies indicate that self-management concerns appear at least as often as health-related concerns with some $50 \%$ of patients describing 'diabetes related management' as their major concern.

Concerns of patients also appear in descriptive studies using interviews and focus groups. Results of these studies suggest that patients are not so much concerned about the long-term threats to their health but rather focus on the short-term impact of medical treatment and lifestyle changes on their daily lives, diet in particular (Everett \& Kerr, 1998; Gillibrand \& Flynn, 2001). Furthermore, for many patients having diabetes was synonymous with having to take injections, a topic which many patients were concerned about regardless of whether it was part of their treatment (Beeney et al., 1996; Everett \& Kerr, 1998). Patients wished to appear and act as normal as possible and continue their lives as usual, minimising the intrusiveness of the diabetes (Gillibrand \& Flynn, 2001; Ho" rnsten, Sandstro"m, \& Lundman, 2004).

\section{Summarising emotional responses}


Thoolen, B., Ridder, D. de, Bensing, J., Gorter, K., Rutten, G. No worries, no impact? A systematic review of emotional, cognitive, and behavioural responses to the diagnosis of type 2 diabetes. Health Psychology Review: 2008, 2(1), 65-93

A total of 16 studies examined emotional outcomes in newly diagnosed patients, including five category 2, 10 category 3 and one category 4 study. Overall, the studies indicate that there is considerable variation in patients' reactions at diagnosis. Up to one half may experience negative emotions, but mild and even predominantly positive emotions (e.g., relief and affirmation) at diagnosis are not uncommon. The more robust (category 2 and prospective category 3) studies confirm that the diagnosis of type 2 diabetes has only limited long-term emotional impact, if at all. As expected, screening was also found to have little emotional impact in the short and long-term. Interestingly, some studies suggest that variations in emotional responses may be more related to patients' symptom experience than the manner of diagnosis.

The more descriptive observational studies (category 3 and 4) supported the findings described above, but also gave more insight into the content of patients' worries and concerns. These studies show that the majority $(60=80 \%)$ of patients do appear to have worries and concerns with regard to their illness. This indicates that global and abstract measures of emotions may not always grasp the underlying concerns and worries whcih people may have (Polonsky, 2000). With regard to content, issues related to managing the illness (e.g., self-care) were mentioned at least as often as health-related concerns. Taken together these studies suggest that, for newly diagnosed patients, the day-to-day self-care can be more intrusive than the long-term complications. This does not, however, necessarily lead to strong emotional responses.

\section{Cognitive responses}

In total, 15 studies examined the beliefs, perceptions and attitudes of newly diagnosed patients. The predominant themes were perceptions of the health threat, patients' selfefficacy, and perceived controllability of the disease. These themes will be discussed below, again distinguishing between screen-detected and other newly diagnosed patients.

\section{Perceptions of the health threat}

Eight studies explicitly investigated threat perceptions; four focused on screen-detected patients, four on patients regardless of their diagnosis. These included one category 2 study and seven category 3 studies.

Screen-detected patients. Adriaanse and associates used questionnaires to investigate perceived risk and seriousness among participants prior to a screening trial $(\mathrm{n}=4437)$ (of which 227 screen-detected patients) (2003) and interviews to assess patients' perceptions two months later $(n=20)$ (2002). Some $60 \%$ of participants considered diabetes to be (very) serious, but they generally underestimated their personal risk. People more at risk gave better risk estimates, but they also considered diabetes to be less serious; screendetected patients, in particular, were less likely to perceive diabetes to be serious. When screen-detected individuals were subsequently interviewed, only 1 in 20 patients considered his or her own diabetes to be serious; 70\% described their condition as mild. Eborall and colleagues (2007a, 2007b) also found in their interviews with a small subsample of screendetected patients that 7 out of 8 emphasised the lack of severity of their condition.

Other studies on screen-detected patients show similar results. Skinner and associates (2006a, 2006b) examined threat perceptions of screening participants $(n=1187)$ and found that $59 \%$ agreed diabetes was serious, but only $37 \%$ expected diabetes to have a negative impact on their life, if diagnosed. Participants who considered diabetes to be more serious and have more consequences were also more anxious at screening. However, perceptions of newly diagnosed patients were not compared to diabetes free individuals. Finally, Thoolen and associates (2006) examined perceived seriousness and personal vulnerability (consequences) in screened patients $(\mathrm{n}=196)$ detected $3=33$ months previously and found that $48 \%$ perceived diabetes to be serious but only $28 \%$ considered their own diabetes to be serious. These threat perceptions increased with time since diagnosis and number of 
Thoolen, B., Ridder, D. de, Bensing, J., Gorter, K., Rutten, G. No worries, no impact? A systematic review of emotional, cognitive, and behavioural responses to the diagnosis of type 2 diabetes. Health Psychology Review: 2008, 2(1), 65-93

complaints, while perceived vulnerability was positively associated with all measures of emotional distress $(r=0.45, \mathrm{p}<0.01)$.

Other newly diagnosed. Four studies examined perceptions of health threats in other newly diagnosed patients (all category 3). One prospective study followed patients for two years after diagnosis, the other three studies were observational descriptive studies. With regard to the prospective study, Lawson and associates found that, immediately after diagnosis, patients ( $\mathrm{n}=158)$ scored relatively low on a scale measuring worries about health consequences ( $M=1.8, S D=0.7$ on a scale from 1 to 5 ); furthermore, levels declined significantly up till two years after diagnosis, suggesting that patients became increasingly less concerned with the potential threats to their health in the first years after diagnosis.

The three descriptive observational studies on newly diagnosed patients indicate that the majority do consider diabetes to be a serious health threat. However, as with screendetected patients, they generally do not reflect this on their own condition and also tend to avoid thinking about future potential threats (Dietrich, 1996; Gillibrand \& Flynn, 2001, Lawton, Peel, Parry, Aroaz, \& Douglas, 2005). Asymptomatic patients have a particularly difficult time accepting their diagnosis, needing more confirmation than other patients (Peel et al., 2004) and, as with screen-detected patients, generally do not give their diabetes any personal meaning (Adriaanse et al., 2002).

\section{Self-efficacy and controllability}

Perceptions of treatment effectiveness, control and self-efficacy give an indication of how well patients feel able to deal with the potential health threat of diabetes. Nine studies discussed these perceptions (eight category 3, one category 4). Three studies focused on screen-detected patients, six on newly diagnosed patients in general.

Screen-detected patients. Interviews with 20 patients, detected two months previously, found that the majority recognised the necessity for lifestyle change. More than half felt confident that they could do something about their diabetes themselves by adjusting their diet and taking medication (Adriaanse et al., 2002). A study assessing self-efficacy among 196 screen-detected patients found that three-quarters reported a high confidence that they could manage their disease but significantly less were actually engaged in self-care (Thoolen et al., 2006). Finally, in interviews with eight screen-detected patients, Eborall and associates (2007a, 2007b) found that all patients talked confidently about their ability to control the disease.

Other newly diagnosed. The six studies on other newly diagnosed patients also found that more than half were confident about their self-management ability (Dietrich, 1996; Everett \& Kerr, 1998; Gillibrand \& Flynn, 2001; Lawson et al., 2007, 2008; Pibernik-Okanovic et al., 1996; Richards \&Morris, 2001). In their prospective two-year follow-up study with 158 newly diagnosed patients, Lawson and associates found that, at diagnosis, patients scored high on measures of treatment effectiveness and personal control (4.0 and 4.2 respectively, $\mathrm{SD}=0.4$ (range $1=5$ )), and these cognitions did not vary during the two year period, suggesting that patients remained confident in their ability to control their disease. The five remaining studies were observational with regard to cognitive outcomes. Pibernik- Okanovic and associates found that $74 \%$ of patients $(n=71)$ felt able to cope with the disease two weeks after diagnosis while Richards and colleagues found that 'nearly all' patients were (very) confident in their self-care three months after diagnosis, particularly with regard to exercise and dietary goals. Finally, three studies using interviews found that being diagnosed with diabetes can also diminish patients' feeling of control over their life, as they become increasingly dependent on health care providers and specific medical regimens (Dietrich, 1996; Everett \& Kerr, 1998; Gillibrand \& Flynn, 2001). In the one study examining this relationship (in screen-detected patients), lower self-efficacy was indeed associated with higher emotional distress (Thoolen et al., 2006). 
Thoolen, B., Ridder, D. de, Bensing, J., Gorter, K., Rutten, G. No worries, no impact? A systematic review of emotional, cognitive, and behavioural responses to the diagnosis of type 2 diabetes. Health Psychology Review: 2008, 2(1), 65-93

\section{Summarising cognitive responses}

More than half of the studies examined cognitions in newly diagnosed patients, but only two studies had a prospective design and only one could be considered to fall into category 2. The remainder fell in category 3 or 4 and often described outcomes without indicating their prevalence. Nevertheless, the available evidence is remarkably consistent and provides an interesting starting point for understanding the way newly diagnosed patients perceive their condition. Overall, the findings indicate that patients with type 2 diabetes downplay the seriousness of their disease and overrate their ability to control it.

This appears to have adaptive value, as those patients who perceived their disease as less serious also reported less emotional distress (three studies) while higher self-efficacy was also associated with lower emotional distress (one study). However, from a behavioural perspective, it is questionable whether these unrealistic perceptions of threat and controllability are conducive to an optimal self-care. More in general, these processes illustrate the importance of perceived control and related constructs such as unrealistic optimism and confirm the often found tendency of people to be overly optimistic; underestimating their susceptibility to health threats (Weinstein, 1987) and overestimating the controllability of uncertain processes (Langer, 1975). These tendencies often reduce the likelihood of people to take preventive action, particularly when these behaviours focus on long-term health goals in a distant future which are easy to discount (Aspinwall, 2005; Chapman, 2003). Indeed, newly diagnosed patients are particularly focused on the shortterm impact which diabetes has on their daily lives, in which diabetes treatment is often considered more intrusive and problematic than long-term complications.

\section{Behavioural responses}

Seven studies investigated specific self-management behaviours in newly diagnosed patients. Of these, three were prospective but only one study could be considered to fall into the second category (Edelman et al., 2002). The remainder were category 3 studies as they either did not include a control group or a longitudinal component. Four focused on screendetected patients, three on newly diagnosed patients in general.

\section{Screen-detected}

A study among 196 screen-detected patients found that most patients report low selfmanagement in the first year after diagnosis with scores comparable to patients diagnosed two to three years previously (Thoolen et al., 2006). Medication adherence was higher than dietary and exercise behaviours. Findings were based on participants planning to take part in a self-management intervention; non-participants reported slightly, but significantly more self-management behaviours at baseline (Thoolen et al., 2007a,b).

The three other studies on screen-detected patients focused on physical activity and included two observational studies and one prospective study. Baan, Stolk, Grobbee, Witteman, \& Feskens (1999) compared 118 screen-detected patients with 153 subjects with insufficient (IGT) and 745 with normal glucose tolerance. They found that time spent on physical activity decreased significantly with increasing IGT, while screen-detected diabetes patients showed the lowest activity scores. However, given that activity levels were only assessed at time of screening, it does not indicate how patients subsequently respond in terms of self-care. A similar study assessed physical activity comparing new screen-detected patients ( $\mathrm{n}=71$ ) with non-diabetics (1100), but also included 97 patients diagnosed in the general practice in the last four years (Fulton-Jehoe, Hamman, Baxter, \& Marshall, 2001). Patients with diabetes reported significantly lower levels of physical activity than those without diabetes, although this relationship diminished when controlling for BMI.

There were no significant differences between newly detected patients and those diagnosed longer ago. Finally, Edelman and colleagues (2002) prospectively examined changes in exercise behaviours over one year, comparing screen-detected and diabetes-free patients (category 2). Exercise levels did not differ at baseline and there were no significant changes 
Thoolen, B., Ridder, D. de, Bensing, J., Gorter, K., Rutten, G. No worries, no impact? A systematic review of emotional, cognitive, and behavioural responses to the diagnosis of type 2 diabetes. Health Psychology Review: 2008, 2(1), 65-93

twelve months later. However, the population was limited to male outpatients, the majority of which were suffering from (multiple) comorbidities. Taken together, these findings suggest that screen-detected patients report relatively low levels of self-management at diagnosis and do not improve over time.

\section{Other newly diagnosed}

The remaining studies (all category 3) examined dietary behaviours (two) and glucose monitoring (one) in newly diagnosed patients. Miller and Brown (2005) prospectively examined 20 couples' adjustment to dietary management of type 2 diabetes in the first two years after diagnosis using repeated interviews. Three categories emerged, representing the flexibility, roles, rules and communication which couples shared in adapting to their diet. Initially, five couples were cohesive (teamwork approach), seven were enmeshed (nondiabetic spouse responsible for the diet) and eight were disengaged (patient solely responsible). A year later, the majority of couples were disengaged $(n=14)$, one couple remained cohesive, and four couples remained enmeshed. Although dieting was not explicitly measured few patients considered themselves successful dieters, citing personal problems, barriers, and interpersonal conflicts. Success was primarily perceived to be a question of willpower. Another study also examined diet in 16 newly diagnosed patients, interviewed in the first session of a counselling programme (Kasila, Poskiparta, \& Kettunen, 2003). One month after diagnosis, all patients recognised the need for diet, but less than half were actively dieting; the majority (nine) were still in the contemplative or preparatory stage of change and had not taken action, five were actively engaged in improving various aspects of dietary self-care, and only two patients reported no need for change.

Lawton, Peel, Douglas, and Parry (2004) prospectively examined glucose monitoring in 40 newly diagnosed patients using three interviews at 0,6 and 12 months. The number of patients monitoring their blood-sugar levels increased from half to two-thirds at one year. Monitoring had the potential to both stimulate and undermine self-care behaviours: it heightened patients' awareness of their asymptomatic condition and the impact of lifestyle but could also amplify a sense of failure when readings remained consistently high.

Patients who were more positive were more successful in controlling their diabetes.

\section{Summarising behavioural responses}

The number of studies on behaviour in newly diagnosed diabetes was limited $(\mathrm{n}=7)$ and included only three prospective studies of which one was category 2. Furthermore, all studies based their findings on self-reports. The limited evidence is remarkable when one considers the vast amount of literature devoted to self management and diabetes, and indicates an important gap in research on diabetes. That said, the findings of this review correspond with more general literature on diabetes self management (Glasgow \& Eakin, 1998; Peyrot et al., 2005). Overall, the findings suggest that both screen-detected and other newly diagnosed patients are not sufficiently engaged in self-management activities, lifestyle behaviours such as diet and physical exercise in particular... The inclusion of descriptive observational studies gave more insight into the reasons why patients do not engage in self-care. For example, Kasila and associates (2003) showed that patients are aware of the need to change but generally have not taken decisive action in terms of concrete intentions. Miller and Brown (2005) describe the many barriers which patients can face in attempting to change their lifestyle. Both studies thus illustrate factors underlying the gap between attitude, intentions and behaviour (Webb \& Sheeran, 2006).

\section{Adjusting to type 2 diabetes: integrating emotional, cognitive and behavioural responses}

In the previous section, we described patients' emotional, cognitive and behavioural responses following the diagnosis of type 2 diabetes. It is important to note that the interaction between these responses is the prime determinant of how patients adjust to their 
Thoolen, B., Ridder, D. de, Bensing, J., Gorter, K., Rutten, G. No worries, no impact? A systematic review of emotional, cognitive, and behavioural responses to the diagnosis of type 2 diabetes. Health Psychology Review: 2008, 2(1), 65-93

illness. Some evidence for this impact on how patients adjust was found in the relationship between patients' perceptions of the seriousness and controllability of their disease, how these affect their lives, and the emotional distress they experience.

Unfortunately, most of the prevailing research tends to focus on one specific category of responses; that is, emotions, cognitions or behavioural outcomes.

Four studies included in the present review took a more general, integrative approach; including one category 2 study and three category 3 studies of which one was prospective.

In their prospective controlled study, (category 2) Pibernik-Okanovic and colleagues (1996) found that patients who adopted more positive attitudes toward their diagnosis at two weeks, generally felt better able to cope and showed better metabolic control and weight loss at twelve months. Similarly, in a retrospective observational study, Lo and Maclean (2001) found that levels of positive emotions were related to successful adherence, while negative emotions undermined health behaviours. Premorbid beliefs, especially beliefs concerning risk and lifestyle also determined long-term coping and self-management behaviour. In a third study, interviews with patients at the extremes of good and poor metabolic control found that the most committed patients were those who had spent little time grieving, quickly taking responsibility for their illness (Savoca, Miller, \& Quandt, 2004). At the other extreme were patients who were overwhelmed, had considerable psychosocial problems, little understanding of their illness, and also little energy or priority to deal with it. Another study showed that receiving a diagnosis is not the same as accepting it (Ho"rnsten et al., 2004). Patients must first reconcile their emotions and accept their role as a patient before they can begin to deal with their illness. Even then, daily hassles and other life problems can interfere with self-management, override long-term health goals and undermine new routines. All four studies illustrate the importance of emotional, cognitive and behavioural aspects in adjustment. The first two studies base their conclusions on statistical analyses of questionnaires; the latter two on content analysis of in-depth interviews.

All in all, it appears that patients who show less emotional and psychosocial distress at diagnosis and a better understanding of their disease in terms of risk and controllability, also show better self-care and control of their disease in the long run, although even in these patients, levels of self-care remain modest. Evidence suggests that many recently diagnosed patients may generally not experience severe emotional distress or bereavement, but they are also far from integrating the illness and the necessary self-care behaviours into their lives.

\section{Variations in psychological responses}

The articles included in this review also reveal considerable variations in patients' responses to diagnosis. In part, these may be related to specific characteristics of the patient, including psychological status at diagnosis (e.g., Lawson et al, 2007; Skinner et al., 2006aSkinner et al., 2006b) and social resources such as social support, education, income and ethnic background (e.g., Ho"rnsten et al., 2004; Pibernik-Okanovic et al., 1999; Savoca et al., 2004). In this section, we focus on factors related to the diagnostic process; most notably, the role of symptoms, prior knowledge and information provision, and medical treatment.

\section{The role of symptoms}

Ten of the studies indicate that symptom experience influences patients' reactions at and beyond the diagnosis, none of the studies refuted this relationship. Contrary to expectations, many patients have been found to have diabetes related symptoms at diagnosis (screendetected patients included); however, few experience them as such (Adriaanse et al, 2002; Koopman, Manous, \& Jeffcoat, 2004; Parry, Peel, Douglas, \& Lawton, 2004). For example, Parry and associates found that $52 \%$ of the patients were diagnosed after visiting their GP for diabetes related symptoms, yet only half of these recognised them as such.

In terms of emotional responses, three interview-based studies found that patients who experienced and recognised their diabetes-related symptoms reported being less surprised 
Thoolen, B., Ridder, D. de, Bensing, J., Gorter, K., Rutten, G. No worries, no impact? A systematic review of emotional, cognitive, and behavioural responses to the diagnosis of type 2 diabetes. Health Psychology Review: 2008, 2(1), 65-93

and were relieved that symptoms were not a reflection of other worse illnesses (Adriaanse et al., 2002; Peel et al., 2004; Savoca et al., 2004). Nevertheless, in three studies using validated measures, higher symptom distress was significantly associated with more emotional distress in the first year after diagnosis, most likely a direct reflection of poorer health (Adriaanse et al., 2002; Dietrich, 1997; Gillibrand \& Flynn, 2001; Hornsten et al., 2004).

In terms of cognitions, Thoolen and associates (2006) found that number of complaints had a weak positive association with perceived vulnerability and a weak negative association with self-efficacy (2006). Four narrative studies suggest several underlying cognitive processes (Adriaanse et al., 2002; Dietrich, 1997; Gillibrand \& Flynn, 2001; Hornsten et al., 2004). These studies describe patients' tendency to downplay their own condition by comparing themselves to more symptomatic patients. The studies also report that many patients only begin to experience distress when the first symptoms appear: not feeling sick means not being sick.

Although many studies suggest a relationship between symptom levels and perceptions of threat and controllability, direct evidence for this relationship is weak. Unfortunately, not a single study examined the influence of symptom levels on behaviour. Furthermore, only two studies were prospective, and only one was controlled (category 2). Nevertheless, the available evidence suggests that the experience and recognition of diabetes related symptoms do influence patients' adjustment. More generally, numerous studies have investigated the manner in which patients' previous experience with illness and with other patients can influence their interpretation of symptoms (e.g., Weinstein, 1989). For example, social comparison theory could be used here to explain the tendency for patients to compare themselves favourably to more symptomatic patients (Taylor \& Lobel, 1989).

\section{Prior knowledge and subsequent information provision}

Nine observational (category 3) studies indicate that newly diagnosed patients have only superficial knowledge of the causes, consequences and treatment of diabetes (Dietrich, 1996; Gillibrand \& Flynn, 2001; Koopman et al., 2004; Peel et al., 2004; Skinner et al., 2006a, 2006b). For example, 59\% of patients were unable to give an explanation for their diagnosis (Richards \& Murphy, 2001) and 70\% of screen-detected patients did not grasp the personal relevance of medical information (Adriaanse et al., 2002). Three studies report that lack of knowledge can exacerbate the uncertainty experienced by many patients; on the other hand, it can also cause (asymptomatic) patients to avoid considering long-term health threats and the need for self-care (Beeney et al., 1996; Gillibrand \& Flynn, 2001, Adriaanse et al., 2002). The only prospective study dealing with this issue indicates that patients experience an increased understanding of diabetes during the first two years after diagnosis (Lawson et al., 2007, 2008). Six category 3 studies describe how relatives and friends with diabetes can be an important source of information, increasing patients' understanding of their illness (Adriaanse et al. 2003; Dietrich, 1997; Gillibrand \& Flynn, 2001; Horsten et al., 2002; Peel et al., 2004; Skinner et al., 2006a, 2006b). According to Peel and associates (2004), this previous experience with diabetes makes patients more 'prepared', i.e., it helps to diminish negative emotions and increase acceptance. However, based on the three studies that attempted to quantify this relationship, we can draw no firm conclusions (Adriaanse et al, 2003, Lawson et al., 2008; Skinner et al, 2006a,b). Lawson and associates (2008) found that having a relative with complications had no effect on understanding or perceptions of threat or control, and was associated with more negative emotional responses. Skinner et al. (2006a, 2006b) found no relationship between family history and affective outcomes or threat perceptions. Finally, Adriaanse and associates (2003) did find a significant association between a family history of diabetes and threat perceptions. Interestingly, interviews with a subsample of 20 patients suggested that experience with other diabetics may also lead patients to downplay their own relatively mild condition (Adriaanse et al., 2002). The lack of 
Thoolen, B., Ridder, D. de, Bensing, J., Gorter, K., Rutten, G. No worries, no impact? A systematic review of emotional, cognitive, and behavioural responses to the diagnosis of type 2 diabetes. Health Psychology Review: 2008, 2(1), 65-93

a single line of evidence could be explained from the perspective of social comparison theory. According to this theory, comparing oneself to patients who are worse off can help patients to downplay their condition. However, when seeking information and advice, patients profit more from those who are better off (Taylor \& Lobel, 1989). As such, a family history of diabetes does not necessarily translate into an increased sense of vulnerability; it can have both a positive and negative effect on patients' affective and cognitive outcomes. Eight category 3 studies stress the crucial role of health providers in increasing patients' understanding of their illness (Beeney et al; 1996; Dietrich, 1996; Ho“" rnsten et al, 2004; Lawson et al., 2007, 2008; Parry et al., 2004; Peel et al., 2004; Richards \& Murpy, 2001; Woodcock \& Kinmonth, 2001). For example, Dietrich found that both downplaying and relatively impersonal reactions undermined patients' perceptions and motivation while caring, supportive doctors comforted patients and increased feelings of control. The strongest support for the role of the health professional comes from work done by Lawson and associates $(2007,2008)$, who found that the type of health communication is a determining factor in how patients perceive and adjust to their illness. Health threat messages given at diagnosis were predictive of more negative emotional responses and higher perceived seriousness of diabetes up to two years after diagnosis. Similarly, reassuring messages given at diagnosis were associated with stronger beliefs in the effectiveness of treatment two years later.

Furthermore, several studies showed that, in contrast to what one might expect of a 'bad news' approach, nearly all patients would have preferred more detailed information at diagnosis, and particularly support in dealing with self-management tasks (Beeney et al., 1996; Dietrich, 1996; Gillibrand \& Flynn, 2001; Peel et al., 2004; Richards \& Murphy, 2001). Professionals were often formal, lacked time and did not address patients' concerns.

While professionals tend to focus on metabolic control and long-term treatment goals, patients focus on day-to-day issues such as how they look and feel, being in control of their lives and being able to fit the treatment plan into their daily routine (Beeney et al., 1996; Woodcock \& Kinmonth, 2001).

\section{The role of treatment}

Seven observational (category 3) and two focus-group studies (category 4) examined how treatment may affect adjustment. Treatment of newly diagnosed patients often begins with lifestyle change alone, particularly when they have few cardiovascular risk factors. Six studies suggest that this, in itself, may cause patients to label their disease as less severe and experience less distress (Adriaanse et al., 2002; Dietrich, 1996; Eborall et al., 2007a,b; Everett \& Kerr, 1998; Gillibrand \& Flynn, 2001; Wenzel, 2006). Vice versa, intensifying treatment can be perceived to confirm the seriousness of an illness while it can also make patients feel less in control (Everett \& Kerr, 1998; Gillibrand \& Kerr, 2001). However, only two studies explicitly examined this relationship. Adriaanse and associates (2004) found that more intensive treatment was not significantly related to emotional outcomes; however, newly diagnosed patients $(n=165)$ who received oral hypoglycaemic agents improved significantly in the first year in terms of both their mental and physical health, while those who only received lifestyle advice did not. Thoolen and colleagues (2006) found that recently detected patients receiving intensive pharmacological treatment reported significantly more distress and less self-efficacy than patients receiving milder care. This association was significant regardless of patients medical status, as this was controlled for in the study. Distress was particularly high on treatment-related items. However, two to three years after diagnosis, intensively treated patients reported significantly less distress and higher self-efficacy. Furthermore, this study also did not find that more intensive treatment increased perceptions of threat. These findings do suggest that it is important to have a look at both short-term outcomes as well as examining if and how these outcomes change over 
Thoolen, B., Ridder, D. de, Bensing, J., Gorter, K., Rutten, G. No worries, no impact? A systematic review of emotional, cognitive, and behavioural responses to the diagnosis of type 2 diabetes. Health Psychology Review: 2008, 2(1), 65-93

time, after diagnosis. Unfortunately none of the studies above took this prospective approach.

Finally, the medical setting in which treatment takes place has also been suggested to play a role in patients' perceptions of and adjustment to diabetes (Lawton et al, 2005). For example, patients generally considered hospitals, and treatment by a specialist versus the general practitioner, to be a confirmation of the seriousness of their condition. Longer delays in treatment of specialists may, in turn, convey less concern.

\section{Summary: individual variations in adjustment}

Overall, the notion that symptoms, knowledge, information provision and treatment influence patients' emotional, cognitive and behavioural responses seems logical but cannot be confirmed among patients newly diagnosed with type 2 diabetes. All but one study fell in the category 3 or 4 , and few of these were prospective. There is some evidence that a lack of symptoms, a low level of knowledge, and experience with diabetes in one's family or circle of friends undermine perceptions of diabetes as a serious health threat, but more research is needed. All relevant studies emphasise the influence which physicians' communication styles can have on patients' adjustment. The effects of different treatments and settings on patients' responses is less evident, but evidence suggests that more intensive treatments may improve their adjustment in the long run.

\section{DISCUSSION}

In this review, we investigated the emotional, cognitive and behavioural responses of patients newly diagnosed with type 2 diabetes. Previous research has shown that screening for asymptomatic conditions such as type 2 diabetes has little emotional impact (Adriaanse et al., 2006; Shaw et al., 1999). This review extends this work to include patients diagnosed via other routes and confirms that the diagnosis has only a limited and short-term impact on experienced emotions, regardless of the manner of diagnosis. Our results do not confirm the myth of emotional turmoil and bereavement after diagnosis (Lorig et al., 2000); patients report a variety of responses but do not go through a set series of emotional stages in accepting and integrating their illness (Kubler-Ross, 1969). Diabetes is no different from other illnesses in that patients who are chronically ill generally appear to adjust quite quickly to their diagnosis (Cassileth et al., 1984).

We would also like to stress the importance of looking beyond emotional outcomes, and address cognitive and behavioural responses. Our findings indicate that newly diagnosed patients tend to downplay the seriousness of their disease, overestimate their ability to control it, and appear just as concerned about avoiding the daily hassles of the disease and its treatment as they are about dealing with the long-term implications to their health. Ultimately, relatively few patients are successfully achieving lifestyle changes in the first year after diagnosis. Both social cognitive and self-regulation theories stress the importance of realistic attitudes or personal models of illness as a precursor for behaviour change (Cameron \& Leventhal, 2003; Connor \& Norman, 2005). From that perspective, the unrealistic appraisals which patients have of their condition and treatment provide one explanation for the low self care reported by most patients. More in general, these processes illustrate the tendency of people to be overly optimistic; underestimating their susceptibility to health threats (Weinstein, 1987), overestimating their ability to control uncertain processes (Langer, 1975), and comparing themselves favourably to those who are worse off (Taylor \& Lobel, 1989). These outcomes suggest that newly diagnosed patients do have difficulty in accepting their diagnosis. While distress remains minimal, patients also avoid addressing the realities of their illness. Wiebe and Korbel (2003) have described this type of response as 'reality based defensive denial', a set of subconscious defensive processes that help to understand threatening information while simultaneously alleviating emotional distress. These rational processes include minimising the health threat, using self-serving social 
Thoolen, B., Ridder, D. de, Bensing, J., Gorter, K., Rutten, G. No worries, no impact? A systematic review of emotional, cognitive, and behavioural responses to the diagnosis of type 2 diabetes. Health Psychology Review: 2008, 2(1), 65-93

comparisons, and biased processing of health information. The fact that patients are not truly accepting the realities of their diagnosis and are not actively engaging in self-care could also help to explain why they are not experiencing emotional turmoil. Indeed, most convincing were the studies on screen-detected patients showing that lower threat perceptions were associated with less distress.

Such processes of defensive denial have been established for a wide range of diseases, including other asymptomatic conditions such as hypertension and hypercholesterolemia (Cameron \& Leventhal, 2003). Indeed, in one of the pioneering self-regulation studies, it was shown that new hypertensive patients tended to consider their condition acute and curable, only slowly recognising the chronic nature of their illness (Baumann, Cameron, Zimmerman, \& Leventhal, 1989). Studies among patients with type 2 diabetes suggest that such defensive denial is effective in minimising emotional turmoil after diagnosis. More positive emotional outcomes are associated with the best metabolic control in the long run (e.g., PibernikOkanovic et al., 1996). However, there is some concern that inexperienced and asymptomatic patients will continue to avoid dealing with their illness until the first signs of exacerbations (e.g., symptoms and treatment intensification) appear, thereby undermining the effectiveness of earlier detection and treatment.

The few studies examining patients' behaviour in more detail indicated that most newly diagnosed patients are aware that self care is an important component of diabetes management (e.g., Kasila et al., 2003, Miller \& Brown, 2005), but many patients fail in their self care due to significant barriers. This indicates that succesful self management is not only a question of attitudes and motivation, but also of the practical realisation of ones intentions (i.e., the intention behaviour gap). Indeed, many patients may report high selfefficacy, but when asked about their primary concern, more than half of the patients refer to the daily hassles of self- care activities as a central issue, suggesting that they may not be adequately equipped to engage in an optimal self management. Theories on future oriented thinking indicate that people who are more proactive (e.g., willing and able to invest in their future) are more successful in achieving desired outcomes and avoiding future threats to their health (Aspinwall, 2005). Yet more general studies on temporal decision making show that people tend to discount large future gains and losses in favour of short-term gains (Chapman, 2003). This could hold particularly true in the case of diabetes in which patients can live years without experiencing any significant symptoms or complications (Heine, 1999).

The presence or absence of symptoms does appear to be an important factor influencing patients' adjustment to type 2 diabetes. It is also important whether or not patients experience their symptoms as such. The evidence we presented suggests that asymptomatic patients do indeed minimise the seriousness of the disease and compare themselves with patients who are worse off via favourable social comparisons (Taylor \& Lobel, 1989). If not feeling ill means not being ill, a large proportion of 'asymptomatic' patients could very well continue their unhealthy lifestyles until, sometimes irreversible, complications appear.

We also identified other factors that may influence patients' adjustment. Research reported in this review indicates that many newly diagnosed patients do not yet understand the full impact of their illness, regardless of family history. They are interested in getting more information, and particularly on how to incorporate treatments into their daily lives as smoothly and painlessly as possible. Health professionals can play an important role in this process. However, they do not always recognise patients' concerns and often focus more on long-term health threats and not enough on treatment (e.g., Woodcock \& Kinmonth, 2001). There is some evidence that treatment may influence psychological outcomes in the long run (Dunning, 1998) and this is supported by the studies included in this review. However, it needs to be added, two more objective studies (one category 2 and one well designed category 3 study) found that intensive treatments may initially be more distressing, but also indicated patients are generally better off in the long run, both physically and mentally, due to health improvements (Adriaanse et al., 2004; Thoolen et al., 2006). It is questionable, 
Thoolen, B., Ridder, D. de, Bensing, J., Gorter, K., Rutten, G. No worries, no impact? A systematic review of emotional, cognitive, and behavioural responses to the diagnosis of type 2 diabetes. Health Psychology Review: 2008, 2(1), 65-93

however, whether asymptomatic patients will be equally appreciative of such intensive treatments.

A limitation of this review is that we had to rely on a limited number of studies.

Moreover quite a few of these studies were observational, narrative and often retrospective, falling into the lowest two categories of the review system of the NHLB (category 3 and 4).

Based on the quality and number of studies, we feel that we can draw strong conclusions about the emotional outcomes, but need to be more careful with regard to interpreting the cognitive and behavioural outcomes. Cognitive outcomes were addressed in fourteen studies, but only one was prospective, and none had controlled designs. Conclusions on behavioural outcomes were based on seven studies and included only three with a prospective design and one controlled study. Given the reliance on narrative and relatively small studies, some of our findings need more empirical evidence before firm conclusions can be drawn. However, the conclusions drawn here present good starting points for further research. That said, the last few years have seen a growing number of sound empirical studies, focusing on screendetected patients in particular. This might reflect a general awareness that we need to understand the psychological impact of screening and early diagnosis and treatment before such programmes are implemented.

In summary, we have shown that a lack of emotional distress does not necessarily indicate successful adjustment in the first year after diagnosis. A substantial number of patients feel unconcerned about the long-term threat to their health and are primarily concerned with minimising the intrusiveness of the disease on a day-to-day level. Not engaging in self-care is part of this process and is quite understandable for patients who are, as of yet, asymptomatic. However, from a medical point of view, the importance of early medical treatment and lifestyle change is widely acknowledged, regardless of symptom experience. This review stresses the importance of making patients aware of the long-term implications of diabetes while simultaneously supporting them in their day-today self-care tasks, minimising the intrusiveness of the disease in both the short and long term. It thereby emphasises both the importance of addressing patient's personal models of illness as well as providing them with the necessary skills to bridge the intention behaviour gap. An increasing number of interventions have begun focusing on newly diagnosed patients and these interventions appear to be (mildly) effective in increasing patients' knowledge, self-care and metabolic control, particularly when they combine educational discussions with selfregulatory skills such as goal-setting, planning and problem solving (Olivarius, BeckNielsen, Andreasen, Horder, \& Pederson, 2001; Skinner, Carey, Cradock, Daly, \& Davies, 2006a; Thoolen et al., 2007a,b; Thoolen, de Ridder, Bensing, Gorter, \& Rutten, in press; Tudor-Locke, Myers, Bell, Harris, \& Rodger, 2002). This suggests that newly diagnosed patients with diabetes may be a particularly interesting group on which to focus.

Given the above, it must be recognised that diabetes takes a unique position within the literature on chronic disease adjustment. Up till now, the majority of studies examining reactions to diagnosis have focused on life-threatening or physically debilitating diseases, such as cancer (e.g., Anderson, Golden-Kreutz, \& DiLillo, 2001) or rheumatoid arthritis (e.g., Walker, Jackson, \& Littlejohn, 2004). In the case of diabetes, there is a vast array of studies, but most focus on patients with longstanding diabetes, Less attention has been given to initial adjustment in the early stages of more asymptomatic and controllable diseases such as diabetes or hypertension. It is clear that there are similarities in patients' emotional adjustment across illnesses; however, the underlying cognitive and behavioural challenges can be very different (Fournier et al., 2002; Heszen-Niejodek et al., 1999).

That said, the rapid developments in medical knowledge have ensured that patients with previously life-threatening and debilitating diseases are experiencing less deterioration and thereby also have to deal with the chronic care of their condition. (De Ridder, Geenen, Kuijer, \& Middendorp, in press). From this perspective type 2 diabetes can be considered the prototype of the chronic disease in which patients are confronted with a scala of selfcare behaviours which may be important for long-term health, but are very disrupting in the short 
Thoolen, B., Ridder, D. de, Bensing, J., Gorter, K., Rutten, G. No worries, no impact? A systematic review of emotional, cognitive, and behavioural responses to the diagnosis of type 2 diabetes. Health Psychology Review: 2008, 2(1), 65-93

term. Self-regulation theories are particularly suited to address this issue, as they recognise that patient's attitudes (personal models) are important, but also look beyond motivational processes and social influences to address the difficulties of translating intentions into sustained behaviours. While the self-regulatory perspective is receiving increasing attention in research, this study indicates that the number of studies focusing on the initial adjustment of newly diagnosed patients is quite limited. As such, this review puts forth a call to examine the viability of this theoretical perspectives in the context of newly diagnosed type 2 diabetes and other chronic conditions.

Finally, this review stresses the importance of looking beyond patients' emotional reactions to diagnosis to consider their perceptions of their disease, and ultimately, how actively they adapt and engage in self-care activities. Patients may experience a wide range of emotional responses, but from a medical viewpoint, whether or not such responses are adaptive ultimately depends on whether or not patients become actively involved in their treatment. In order to increase our understanding it seems essential to look at both emotional, cognitive and behavioural responses to diagnosis and early treatment. This seems the best way to enable the development of more successful screening and intervention programmes.

\section{REFERENCES}

Adriaanse, M.C., \& Snoek, F.J. (2006). The psychological impact of screening for type 2 diabetes.

Diabetes/ Metabolism Research and Reviews, 22, $20 \_25$.

Adriaanse, M.C., Snoek, F.J., Dekker, J.M., Spijkerman, A.M., Nijpels, G., \& Twisk, J.W. (2004a).

Health related quality of life in the first year following diagnosis of type 2 diabetes: The Hoorn screening study. Diabetic Medicine, 21, 1075_1081.

Adriaanse, M.C., Snoek, F.J., Dekker, J.M., Spijkerman, A.M., Nijpels, G., \& Twisk, J.W. (2004b).

No substantial psychological impact of the diagnosis of type 2 diabetes following targeted population screening: The Hoorn screening study. Diabetic Medicine, 21, 992_998.

Adriaanse, M.C., Snoek, F.J., Dekker, J.M., Spijkerman, A.M., Nijpels, G., \& van der Ploeg, H.M.

(2003). Perceived risk for type 2 diabetes in participants in a stepwise population-screening program. Diabetic Medicine, 20, 210_215.

Adriaanse, M.C., Snoek, F.J., Dekker, J.M., van der Ploeg, H.M., \& Heine, R.J. (2002). Screening for type 2 diabetes: Exploration of subject's perceptions regarding diagnosis and procedure. Diabetic Medicine, 19, 1_6.

Aspinwall, L.G. (2005). The psychology of future-oriented thinking: From achievement to proactive coping, adaptation and aging. Motivation and Emotion, 29, 203_234.

Baan, C.A., Stolk, R.P., Grobbee, D.E., Witteman, J.C., \& Feskens, E.J. (1999). Physical activity in elderly subjects with impaired glucose tolerance and newly diagnosed diabetes mellitus. American Journal of Epidemiology, 149, 219_227.

Baumann, L.J., Cameron, L.D., Zimmerman, R.S., \& Leventhal, H. (1989). Illness representations and matching labels with symptoms. Health Psychology, 8, 449_469.

Beeney, L.J., Bakry, A.A., \& Dunn, S.M. (1996). Patient psychological and information needs when the diagnosis is diabetes. Patient Education and Counseling, 29, 109_16.

Cameron, L.D., \& Leventhal, H. (2003). The self-regulation of health and illness behaviour. London: Routledge.

Carver, C.S., \& Scheier, M.F. (1998). On the self-regulation of behavior. Cambridge, UK: Cambridge University Press.

Cassileth, B.R., Lusk, E.J., Strouse, T.B., Miller, D.B., Brown, L.L., \& Cross, P.A. (1984).

Psychosocial status in chronic illness: A comparative analysis of six diagnostic groups. The New England Journal of Medicine, 311, 506_511.

Chapman, G. (2003). Time discounting of health outcomes. In G. Loewenstein, D. Read, \& R.

Baumeister. (Eds.), Time and decision: Economic and psycological perspectives on intertemporal choice (pp. XXXX) New York: Russel Sage Foundation. 
Thoolen, B., Ridder, D. de, Bensing, J., Gorter, K., Rutten, G. No worries, no impact? A systematic review of emotional, cognitive, and behavioural responses to the diagnosis of type 2 diabetes. Health Psychology Review: 2008, 2(1), 65-93

Connor, M., \& Norman, P. (Eds.). (2005). Predicting health behaviour (2nd ed.). Buckingham, UK: Open University Press.

De Ridder, D., \& De Wit, J. (Eds.). (2006). Self-regukation in health behavior. West Sussex, UK: Wiley.

De Ridder, D., Geenen, R., Kuijer, R., \& van Middendorp, H. (2008). Psychological adjustment to chronic disease. Lancet, 372, 246_255.

Dietrich, S. (1996). Factors influencing the attitudes held by women with type 2 diabetes: $A$ qualitative study. Patient Education and Counseling, 29, 13_23.

Doust, J., Mannes, P., Bastian, H., \& Edwards, A. (2003). Interventions for improving, understanding and minimising the psychological impact of screening. Cochrane Database of Systematic Reviews: DOI: .1002/14651858.C, D001212, 10.

Dunning, T. (1998). Beliefs about diabetes and diabetic complications. Professional Nurse, 13, 429_ 437.

Eborall, H., Davies, R., Kinmonth, A., Griffin, S., \& Lawton, J. (2007a). Patients experiences of screening for type 2 diabetes: Prospective qualitative study embedded in the ADDITION (Cambridge) randomised controlled trial. British Medical Journal, 335, 490_495.

Eborall, H., Griffin, S., Prevost, A., Kinmonth, A., French, D., \& Sutton, S. (2007b). Psychological impact of screening for type 2 diabetes: Controlled trial and comparative study embedded in the ADDITION (Cambridge) randomised controlled trial. British Medical Journal, 335, 486_489.

Edelman, D., Olsen, M.K., Dudley, T.K., Harris, A.C., \& Oddone, E.Z. (2002). Impact of diabetes screening on quality of life. Diabetes Care, 25, 1022_1043.

Engelgau, M.M., Venkat Narayan, K.M., \& Herman, W.H. (2000). Screening for type 2 diabetes.

Diabetes Care, 23, 1563 1580.

Everett, K., \& Kerr, D. (1998). A picture of the impact of newly diagnosed type 2 diabetes. Journal of Diabetes Nursing, 2(6), 170_175.

Faith, M.S., Fontane, K.R., Baskin, M., \& Allison, D.B. (2007). Towards reduction of population obesity: Macro-level environmental approaches to problems of food, eating, and obesity.

Psychological Bulletin, 133, 205_226.

Fournier, M., de Ridder, D., \& Bensing, J. (2002). Does optimism affect symptom report in chronic disease? What are its consequences for self-care behaviour and physical functioning? Journal of Psychosomatic Research, 56, 341_350.

Fulton-Jehoe, D., Hamman, R.F., Baxter, J., \& Marshall, J. (2001). A case_control study of physical activity and non-insulin dependent diabetes mellitus. The San Luis valley diabetes study. Annals of Epidemiology, 11, 320_327.

Gillibrand, W., \& Flynn, M. (2001). Forced externalization of control in people with diabetes: A qualitative exploratory study. Journal of Advanced Nursing, 34, 501_510.

Glasgow, R.E., \& Eakin, E. (1998). Issues in diabetes self-management. In S.A. Schumaker \& E.B.

Schron (Eds.), Handbook of health behavior (2nd ed) (pp. 435_461). New York: Springer.

Gollwitzer, P.M. (1999). Implementation intentions. Strong effects of simple plans. American Psychologist, 54, 493_503.

Heine, R. (1999). Diabetes in the next centruy: Challenge and opportunities. The Netherlands Journal of Medicine, 55, 265_270.

Heszen-Niejodek, I., Gottschalk, L.A., \& Jañuszek, M. (1999). Anxiety and hope during the course of three different medical illnesses: A longitudinal study. Psychotherapy and Psychosomatics, 68, 304_312.

Ho"rnsten, A., Sandstro"m, H., \& Lundman, B. (2004). Personal understandings of illness among people with type 2 diabetes. Journal of Advanced Nursing, 47, 174_182.

Kasila, K., Poskiparta, P., \& Kettunen, T. (2003). Patients' readiness for dietary change at the beginning of counselling: A transtheoretical model-based assessment. The British Dietetic Association, 16, 159_166.

Koopman, R.J., Manous, A.G., \& Jeffcoat, A.S. (2004). Moving from undiagnosed to diagnosed diabetes: The patient's perspective. Family Medicine, 36, 727_732.

Kubler-Ross, E. (1969). On death and dying. New York: MacMillan. 
Thoolen, B., Ridder, D. de, Bensing, J., Gorter, K., Rutten, G. No worries, no impact? A systematic review of emotional, cognitive, and behavioural responses to the diagnosis of type 2 diabetes. Health Psychology Review: 2008, 2(1), 65-93

Langer, E.J. (1975). The Illusion of control. Journal of Personality and Social Psychology, 32, 311_328.

Lawson, V., Bundy, C., \& Harvey, J. (2007). The influence of health threat communication and personality traits on personal models of diabetes in newly diagnosed diabetic patients. Diabetic Medicine, 24, 883_891.

Lawson, V., Bundy, C., \& Harvey, J. (2008). The development of personal models of diabetes in the first 2 years after diagnosis: A prospective longitudinal study. Diabetic Medicine, 25, 482490.

Lawton, J., Peel, E., Douglas, M., \& Parry, O. (2004). Urine testing is a waste of time': Newly diagnosed type 2 diabetes perceptions of self-monitoring. Diabetic Medicine, 21, 1045_1048.

Lawton, J., Peel, E., Parry, O., Araoz, G., \& Douglas,M. (2005). Lay perceptions of type 2 diabetes in Scotland: Bringing health services back in. Social Science and Medicine, 60, 1423_1435.

Lo, R., \& Maclean, D. (2001). The dynamics of coping and adapting to the impact when diagnosed with diabetes. Australian Journal of Advanced Nursing, 19, $26 \_32$.

Lorig, K., Holma, H., Sobel, D., Laurent, D., Gonzales, V., \& Minor, M. (2000). Living a healthy life with chronic conditions. Palo Alto, CA: Bull.

Miller, D., \& Brown, J.L. (2005). Marital interactions in the process of dietary change for type 2 diabetes. Journal of Nutrition Education \& Behavior, 37, 226234.

Nichols, G.A., \& Brown, J.B. (2004). Functional status before and after the diagnosis of type 2 diabetes. Diabetic Medicine, 21, 793_797.

Olivarius, N.D., Beck-Nielsen, H., Andreasen, A.H., Horder, M., \& Pederson, P.A. (2001).

Randomized controlled trial of structured personal care of type 2 diabetes mellitus. British Medical Journal, 323, 970_975.

Parry, O., Peel, E., Douglas, N., \& Lawton, J. (2004). Patients in waiting: A qualitative study of type 2 diabetes patients' perceptions of diagnosis. Family Practice, 21(2), 131_136.

Peel, E., Parry, O., Douglas, N., \& Lawton, J. (2004). Diagnosis of type 2 diabetes: Qualitative analysis of patients emotional reactions and views about information provision. Patient Education and Counseling, 53, 269_275.

Peel, E., Parry, O., Douglas, M., \& Lawton, J. (2005). Taking the biscuit? A discursive approach to managing diet in type 2 diabetes. Journal of Health Psychology, 10, 779_791.

Peyrot, M., Rubin, R.R., Lauritzen, T., Snoek, F.,Matthews, D., \& Skovlund, S. (2005). Psychosocial problems and barriers to improved diabetes management: Results of the cross-national diabetes attitudes, wishes and needs (DAWN) study. Diabetic Medicine, 22, 1379 1385.

Pibernik-Okanovic, M., Roglic, G., Prasek, M., \& Metelko, Z. (1996). Emotional adjustment and metabolic control in newly diagnosed diabetic persons. Diabetes Research and Clinical Practice, 34, 99_105.

Polonsky, W.H. (2000). Understanding and assessing diabetes-specific quality of life. Diabetes Spectrum, 13, 36_41.

Renner, B. (2004). Biased reasoning: Adaptive responses to health risk feedback. Personality and Social Psychology Bulletin, 30, 384_396.

Richards, G., \& Morris, M. (2001). Psychological aspects in the diagnosis of type 2 diabetes. Diabetes and Primary Care, 3, 52_55.

Rothman, A.J., \& Salovey, P. (1997). Shaping perceptions to motivate healthy behavior: The role of message framing. Psychological Bulletin, 121, 3_19.

Savoca, M.R., Miller, C.K., \& Quandt, S.A. (2004). Profiles of people with type 2 diabetes:

The extremes of glycaemic control. Social Science and Medicine, 58, 2655_2666.

Shaw, C., Abrams, K., \& Marteau, T.M. (1999). Psychological impact of predicting individual's risks of illness: A systematic review. Social Science and Medicine, 49, 1571_1598.

Sidell, N. (1997). Adult adjustment to chronic illness: Review of the literature. Health and Social Work, 22, 5_11.

Skinner, T.C., Carey, M.E., Cradock, S., Daly, H., \& Davies, M.J. (2006a). Diabetes education and self-management for ongoing and mewly diagnosed (DESMOND): Process modelling of pilot study. Patient Education and Counseling, 64, 369_377. 
Thoolen, B., Ridder, D. de, Bensing, J., Gorter, K., Rutten, G. No worries, no impact? A systematic review of emotional, cognitive, and behavioural responses to the diagnosis of type 2 diabetes. Health Psychology Review: 2008, 2(1), 65-93

Skinner, T.C., Davies, M.J., Farooqi, A.M., Jarvis, J., Tringham, J.R., \& Khunti, K. (2006b). Diabetes screening and beliefs. Diabetic Medicine, 22, 1497_1502.

Snoek, F.J., Adriaanse, M.C., Dekker, J.M., Spijkerman, A.M., Twisk, J.W., \& Nijpels, G. (2005).

Diabetes-related symptoms and negative mood in participants of a targeted populationscreening program for type 2 diabetes: The Hoorn screening study. Quality of Life Research, 14, 15011509.

Stanton, A.L., Collins, C.A., \& Sworowski, L. (2001). Adjustment to chronic illness: Theory and research. In A. Baum, T.A. Revenson \& J.E. Singer (Eds.), Handbook of health psychology (pp. 15_20). Mahwah, NJ: Lawrence Erlbaum Associates.

Taylor, S.E., \& Lobel, M. (1989). Social comparison activity under threat: Downward evaluation and upward contacts. Psychological Review, 96, 569_575.

Thoolen, B.J., de Ridder, D.T., Bensing, J.M., Gorter, K.J., \& Rutten, G.E. (2006). Psychological outcomes of patients with screen-detected type 2 diabetes. The influence of time since diagnosis and treatment intensity. Diabetes Care, 29, 2257_2262.

Thoolen, B.J., de Ridder, D.T., Bensing, J.M., Gorter, K.J., \& Rutten, G.E. (2007a). Who participates in self management interventions? Issues of recruitment and retainments. The Diabetes Educator, 33, 465_474.

Thoolen, B.J., de Ridder, D.T., Bensing, J.M., Gorter, K.J., \& Rutten, G. (2007b). The effectiveness of a self-management intervention in screen-detected type 2 diabetes. Diabetes Care, 30, 2832_2837.

Thoolen, B.J., de Ridder, D.T., Bensing, J.M., Gorter, K.J., \& Rutten, G.E. (in press). Beyond good intentions: The role of proactive coping in achieving sustained behavioral change in the context of diabetes management. Psychology and Health, in press.

Tudor-Locke, C.E., Myers, A.M., Bell, R.C., Harris, S.B., \& Rodger, N.W. (2002). Preliminary outcome evaluation of the first step program. Patient Education and Counseling, 47, 2328.

Walker, J.G., Jackson, H.J., \& Littlejohn, G.O. (2004). Models of adjustment to chronic illness: Using the example of rheumatoid arthritis. Clinical Psychology Review, 24, 461 488.

Webb, T.L., \& Sheeran, P. (2006). Does changing behavioral intentions engender behavior change? A meta-analysis of the experimental evidence. Psychological Bulletin, 132, 249_268.

Weinstein, N.D. (1987). Unrealistic optimism about susceptibility to health problems:

Conclusions from a community-wide sample. Journal of Behavioral Medicine, 10, 481_500.

Weinstein, N.D. (1989). Effects of personal experience on self-protective behavior.

Psychological Bulletin, 105, 31_50.

Wiebe, D., \& Korbel, C. (2003). Defensive denial, affect, and the self-regulation of health threats. In L.D. Cameron \& H. Leventhal (Eds.), The self-regulation of health and illness behaviour (pp. 395_418). New York: Routledge.

Wild, S., Roglic, G., Ḡreen, A., Sicree, R., \& King, H. (2004). Global prevalence of diabetes: Estimates for the year 2000 and projections for 2030. Diabetes Care, 27, 1047_1053.

Wit, J. de, \& Stroebe, W. (2004). Social cognition models of health behaviour. In A. Kaptein $\& \mathrm{~J}$.

Weinman (eds.), Health Psychology (pp. 52_83). Oxford: Blackwell Publishing.

Woodcock, A.J., \& Kinmonth, A.L. (2001). Patient concerns in their first year with type 2 diabetes: Patient and practice nurse views. Patient Education and Counseling, 42, 257_270.

Zimmet, P., Albert, K.G., \& Shaw, J. (2001). Global and societal implications of the diabetes epidemic. Nature, 414, 782_787. 
Thoolen, B., Ridder, D. de, Bensing, J., Gorter, K., Rutten, G. No worries, no impact? A systematic review of emotional, cognitive, and behavioural responses to the diagnosis of type 2 diabetes. Health Psychology Review: 2008, 2(1), 65-93

Results

TABLES

Table 1. Search strategy.

Key terms

Medline Psychinfo Cinahl

1. Type 2 diabetes (niddm, etc.) not child, adolescent or youth,...) and $40,674 \quad 483 \quad 4187$

2. Newly diagnosed (new onset, recent onset, screen*, etc.) and 7245

3a) Emotion* (anger, fear, anxiety, denial, depression, relief ....) or $\quad \begin{array}{llll}94 & 21 & 135\end{array}$

3b) Cognitive (cognit*, attitude*, perception*, belief, personal $\quad$ or $\quad 225 \quad 36 \quad 443$

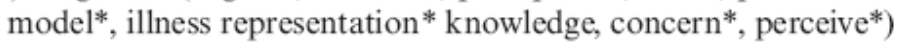

3c) Coping (adjustment, adaptation, reaction, Psychosocial ....) or $\quad \begin{array}{llll}188 & 12 & 222\end{array}$

3d) Adherence (compliance, self-management, self-care beha- $\quad 32 \quad 13 \quad 210$ viour)

Result prior to selection $\quad 469 \quad 49 \quad 497$

Result after selection $\quad 19 \quad 6 \quad 10$

Net result 24

Note: Pubmed, electronic database of the National Library of Medicine (incl Medline); Psychinfo, electonic database of psychological (-related) journals; CINAHL, the Cumulative Index to Nursing and Allied Health Literature (CINAHL). 
Table 2. Overview of studies examining psychological adjustment in newly diagnosed type 2 diabetes.

Prospective, Category 2

\begin{tabular}{llll}
\hline Author/country & Year & Type - No. of participants & Study design
\end{tabular}

Eborall et al. $U K$

$2007 \mathrm{a}, 2007 \mathrm{~b} 7380$ at risk for diabetes

6416 invited for screening

150 screen-detected

Interviews with 25 pts (eight

screen-detected)

Hoorn Screening

Study: Adriaanse

et al. (five publica-

tions 2002-2006).

The Netherlands

116 screen-detected

143 non-diabetics diagnosis $=0$ wks

Prospective study comparing screening

participants (of which 150 diagnosed) with

non-invited (control group) and non-

attenders. Questionnaires on state anxiety,

anxiety and depression, and worry about

diabetes at diagnosis, 3-6 and 12-15 mth

state anxiety, and depression than reported higher effects were small and not clinically relevant. Levels were lower at 3-6 months and 12-15 months and differences were no longer significant. Only $1 / 8$ participants reported shock at diagnosis (interviews. Cognitive: most common reaction was to downplay the disease. All pts confident in controlling their disease.

Prospective study comparing diagnosed and Emotion: The diagnosis had no substantial adverse non-diabetics in a screening. Questionnaires or positive effect on well-being and perceived mental on well being and mental health 2 wks prior health up to one yr after diagnosis. No significant and 2 wks, 6 and 12 mths after diagnosis. difference by treatment.

$2004 \quad 116$ screen-detected 49 diagnosed in GP diagnosis $=0 \mathrm{wks}$

As above, but screen- detected pts compared to those diagnosed in GP. Questionnaires include symptom distress, mental health and well being. 2 wks before to $12 \mathrm{mths}$ after.

246 high risk, of which 116 screened, 130 non-diabetics diagnosis $=0 \mathrm{wks}$

As above, but now comparing screen-detected pts with high-risk non-diabetics.

Emotion: Compared to screen-detected pts, pts diagnosed in GP initially reported more symptom distress and lower well-being and mental health but their outcomes improved significantly at $12 \mathrm{mth}$. Improvement related to treatment.

Emotion: Symptom distress and negative well being low in both groups. No change in 12 mths. Symptom distress higher in screen-detected. Negative well being associated with symptom distress.

$2003 \quad 217$ screen-detected 4435 low-risk diagnosis $=0 \mathrm{wk}$
Observational study, using questionnaires to Cognition: Perceived risk was very low.

assess perceived seriousness of and personal Screen-detected pts were more likely to answer either risk for diabetes prior to diagnosis in

"I'd not know", or rate risk higher. $60 \%$ considered creendetected pts and those with low rist Limit: $\mathrm{pts}$ were unaware of diagnosis at time of assessment. Hence no response.

diabetes to be a (very) serious condition. Pts and 


\section{Prospective, Category 2}

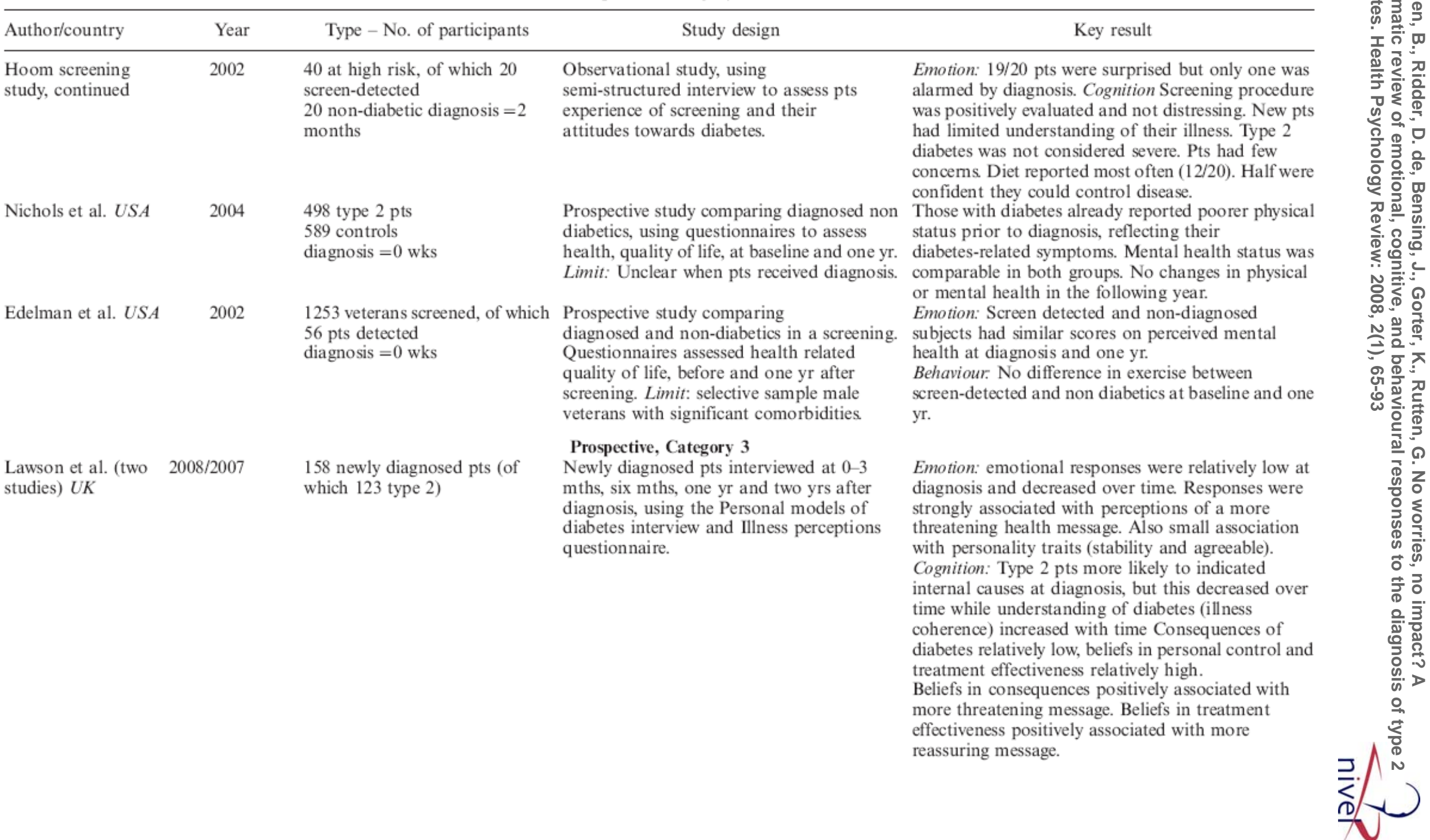


Prospective, Category 2

\begin{tabular}{llll}
\hline Author/country & Year & Type - No. of participants & Study design result
\end{tabular}

Parry, Peel, Douglas 2005/2004 and Lawton (four

publications 2004

2005) $U K$

Miller et al. USA

Pibernik-Okanovic

et al. Croatia

Thoolen et al The

Netherlands
40 newly diagnosed pts with

diabetes diagnosis $=0 \mathrm{wks}$

\section{Series of repeated interviews with pts at or} near diagnosis, six and $12 \mathrm{mths}$, assessing

their manner of and reactions to diagnosis, their perceptions of diabetes (self-care) and the health-care services. Limit: Relative occurrence of emotional and cognitive and outcomes unclear.

20 couples with newly diagnosed spouse diagnosis $<$ one yr

71 diabetics diagnosis $=2 \mathrm{wks}$

\section{A prospective study using questionnaires to} assess pts metabolic control, weight,

emotional adjustment, and coping responses to diagnosis at two wks. Examined most weight loss one yr later. In contrast, the group

prior experience with diabetes, symptoms and treatment. Emotion Shock and negative emotions not prevalent in group who suspected diabetes or approached GP with other health problems. When diagnosis was unexpected, reactions varied but disbelief common. Cognitions: All pts would have liked more information and support at diagnosis, particularly about self-care. Behaviour. Number of pts monitoring blood sugar increased significantly in first yr. Highlights experiences. Examines dieting behaviour, and interpretation of failures.

Behaviour: Three categories emerged, representing couples examining adjustment to dietary management of type 2 diabetes. Limit:
follow up beyond first yr for most pt. No couple's flexibility, roles, rules and communication in adapting to diabetic diet. Shift from cohesive

(teamwork approach) or enmeshed (pt dependent on spouse) to disengaged ( $p t$ solely responsible). Shift to disengaged also reflected failed diet.

Emotion: Two wks after diagnosis, $50 \%$ expressed undisturbed adaptation and sense of being able to yr.

Observational, patients recruited within first year of diagnosis, Category 3

\section{6 screen-detected diagnosis = Observational study Questionnaires as}

3-33 mths
Observational study. Questionnaires as-
sessed pts' emotional (anxiety, depression, distress), cognitive (threat perceptions, self-efficacy) and behavioural (self-management) outcomes, compared time (diagnosis) and treatment. Limit: selective group planning to take part in self-management intervention.
Emotion: Low distress. Distress levels related to treatment Positively associated with vulnerability and complaints. Negatively associated with self-efficacy Cognition: Threat perceptions low but increase with time. $48 \%$ consider diabetes serious, $<30 \%$ consider own diabetes serious. High self-efficacy but lower among intensively treated pts in first yr. Behaviour low self-care. Medication adherence high, diet and exercise low 


\begin{tabular}{lcl}
\hline Author/country & Year & Type - No. of participants \\
\hline Skinner et al $U K$ & 2006a, 2006b & $\begin{array}{l}1189 \text { screened individuals at } \\
\text { high risk for } \\
\text { diabetes diagnosis = not yet }\end{array}$
\end{tabular}

Prospective, Category 2

diabetes diagnosis $=$ not yet

Richards $U K$

$N=56$ pts diagnosed $<$ three mths

1016 screened

Baan et al. The

Fulton-Kehoe et al.

-118 diagnosed type 2

-153 with IGT, and -745 with normal GT diagnosis $=0 \mathrm{wks}$ Observational study. Questionnaires
assessed physical activity, comparing assessed physical activity, comparing
diagnosed, at risk (IGT)and healthy subjects at time of screening. Limit: activity measured at diagnosis, does not indicate change after diagnosis.

1100 non diabetics

71 screen-detected pts 97 pts diagnosed $0-4$ yrs diagnosis $=0 \mathrm{wks}$

Observational study. Questionnaires assessed physical activity, comparing screen-detected pts with other pts and non diabetics.

Limit: same as above, but includes other Observational study using open-ended questionnaire to assess pts and nurses concern regarding diabetes.

\section{$250 \mathrm{pts}$}

diagnosis $=$ one year

15 newly diagnosed pts diagnosis $=<$ six mths
Observational study using interviews to assess manner of diagnosis and potential barriers to getting help.

\section{Key result} impact. $59 \%$ agreed diabetes was serious, but only $12 \%$ agreed with all consequence items. Positive association between perceived seriousness and anxiety. medicationects reported high sell-efficacy for ta medication and following diet but were less confident in ability to control disease. Knowledge of diabetes were unable to explain diagnosis

Behaviour: Time spent on physical activity decreased with increasing glucose tolerance. Screen-detected pts
showed lowest activity scores, particularly with regard to bicycling and sports.

Behaviour. Diabetes pts report significantly lower physical activity than non-diabetics, new detected pts in particular Relationship diminished when controlling for BMI. Differences between pt groups not significant.

Cognition: Pts focus more on the short-and long term burden/restrictions of diabetes. Nurses focus on treatment of bloodglucose levels. main concerns pts: diet, fear of getting worse, damage caused by diabetes.

Cognition: $13 / 15$ pts had experienced diabetes related symptoms but only three pts had recognised them as such. Seven pts still did not recognise their symptoms after diagnosis. Pts had a poor knowledge of diabetes even though $14 / 15$ had relatives with diabetes. 
Prospective, Category 2

\begin{tabular}{|c|c|c|c|c|}
\hline Author/country & Year & Type - No. of participants & Study design & Key result \\
\hline Kasila et al Finland & 2003 & $\begin{array}{l}16 \text { newly diagnosed pts } \\
\text { diagnosis }<\text { one } \mathrm{mth}\end{array}$ & $\begin{array}{l}\text { Observational study analysing initial } \\
\text { counselling sessions with pts to determine } \\
\text { their readiness for changing their dietary } \\
\text { behaviour. } \\
\text { Limits: selective group at start of counseling. }\end{array}$ & $\begin{array}{l}\text { Behaviour. All pts recognised need for diet but less } \\
\text { than half }(7 / 16) \text { were actively dieting. About } \\
\text { one-third }(6) \text { were contemplating change. Three were } \\
\text { making concrete plans to achieve their goals } \\
\text { (preparation). One third ( } 5 \text { ) were actively changing } \\
\text { their behaviour (action). } 2 \text { pts in maintenance stage. }\end{array}$ \\
\hline \multicolumn{5}{|c|}{ Observational, retrospective, Category 3} \\
\hline $\begin{array}{l}\text { Beeney et al. Aus- } \\
\text { tralia }\end{array}$ & 1996 & $\begin{array}{l}1159 \text { diabetes pts, } \\
785 \text { type } 2 \text { pts } \\
374 \text { type- } 1 \\
100 \text { GPs diagnosis = ave } 10 \mathrm{yrs}\end{array}$ & $\begin{array}{l}\text { Observational study using questionnaires to } \\
\text { assess concerns and information preferences } \\
\text { at time of diagnosis. Compared with GP's } \\
\text { perception of pts major concerns. Limit: no } \\
\text { specific attention for newly diagnosed pts. }\end{array}$ & $\begin{array}{l}\text { Emotion: } 60 \% \text { strong emotional reactions. } 28 \% \\
\text { relieved. Cognition: Diet most often major concern at } \\
\text { diagnosis }(21 \%) \text {, followed by injections }(15 \%) \text {, } \\
\text { complications (13\%) and lifestyle }(13 \%) \text {. } 20 \% \text { had no } \\
\text { concerns. GPs expect complications to be pts major } \\
\text { concern. } 80 \% \text { of pts would have preferred more } \\
\text { information and support. }\end{array}$ \\
\hline Lo et al. Australia & 2001 & $\begin{array}{l}109 \text { type- } 1 \\
241 \text { type } 2 \\
\text { diagnosis =ave } 4.2 \text { yrs }\end{array}$ & $\begin{array}{l}\text { Observational study. Questionnaires assess } \\
\text { the coping trajectory of diabetes pts } \\
\text { following diagnosis, including their pre- } \\
\text { morbid lifestyle beliefs, perceived threat, } \\
\text { coping responses and self-care. Limit: } \\
\text { Actual outcomes not reported,only } \\
\text { relationships. }\end{array}$ & $\begin{array}{l}\text { Emotion and cognition: Impact of diagnosis greater } \\
\text { for type } 1 \text { than type } 2 \text { pts. Type } 2 \text { pts more positive, } \\
\text { more likely not to feel ill and need more time } \\
\text { accepting diagnosis. Fear of consequences play a } \\
\text { central role in pts reactions either resulting in } \\
\text { negative emotions, or a positive focus to overcome } \\
\text { challenges. }\end{array}$ \\
\hline Dietrich $U S A$ & 1996 & $\begin{array}{l}7 \text { type } 2 \text { pts diagnosis }= \\
3 \text { wks }-40 \mathrm{yrs}\end{array}$ & $\begin{array}{l}\text { Observational study. Interviews investigated } \\
\text { the pts' attitudes towards their illness and } \\
\text { treatment. Limits: Selective and difficult } \\
\text { recruitment. Small number. No attention for } \\
\text { new pts. }\end{array}$ & $\begin{array}{l}\text { Emotion: } 6 / 7 \text { had strong negative emotions at } \\
\text { diagnosis. Cognition: Most considered diabetes a } \\
\text { serious threat and feared loss of health and disease } \\
\text { taking over one's life. Pts lack knowledge and had } \\
\text { difficulty understanding info. A family history } \\
\text { increased threat perception. Lack of symptoms and } \\
\text { unclear messages by GP decreased threat and } \\
\text { motivation to engage in self-care. }\end{array}$ \\
\hline Gillibrand et al. $U K$ & 2001 & $\begin{array}{l}18 \mathrm{pts}, 15 \text { type } 2 \text { diagnosis }= \\
2-32 \mathrm{yrs}\end{array}$ & $\begin{array}{l}\text { Observational study using interviews to } \\
\text { assess pts' perceptions of diabetes and its } \\
\text { complications. Limits: No differentiation } \\
\text { newly diagnosed and long-term pts. } \\
\text { Indicates responses w/o relative occurrence. }\end{array}$ & $\begin{array}{l}\text { Emotion: All pts reported negative emotions at } \\
\text { diagnosis. Anxiety only truly began when } \\
\text { complications or treatment let pts experience the full } \\
\text { implications of diabetes. Cognition: Major concerns } \\
\text { were complications and lifestyle impact. Discussed } \\
\text { knowledge, information provision and general } \\
\text { responses to diagnosis. }\end{array}$ \\
\hline
\end{tabular}




\begin{tabular}{|c|c|c|c|c|}
\hline \multicolumn{5}{|c|}{ Prospective, Category 2} \\
\hline Author/country & Year & Type - No. of participants & Study design & Key result \\
\hline Savoca et al., USA & 2004 & 44 type 2 pts diagnosis $>$ one $y r$ & $\begin{array}{l}\text { Observational study. Interviews contrasted } \\
\text { experiences and attitudes of people at the } \\
\text { extremes of control. Limit: Selective sample } \\
\text { (poor Afro-americans). }\end{array}$ & $\begin{array}{l}\text { General: Identifying five styles of adjustment to } \\
\text { diagnosis (committed, tentative, hopeful, hassled and } \\
\text { overwhelmed), related to good or poor control. }\end{array}$ \\
\hline $\begin{array}{l}\text { Hörnsten et al } \\
\text { Sweden }\end{array}$ & 2004 & 44 pts diagnosis $<$ two yrs & $\begin{array}{l}\text { Observational study using interviews to } \\
\text { assess pt's understanding of and experience } \\
\text { living with diabetes. Limits: a detailed } \\
\text { description of variety of responses w/o } \\
\text { indicating relative occurrence. }\end{array}$ & $\begin{array}{l}\text { Cognition: Describes the personal understanding of } \\
\text { illness among newly diagnosed pts, primarily stres- } \\
\text { sing the variation along six themes, including image } \\
\text { of the disease, its meaning, integration and space for } \\
\text { illness in one's life, taking responsibility, and future } \\
\text { prospects. }\end{array}$ \\
\hline
\end{tabular}

\section{Focus groups, Category 4}

Emotion: All pts experienced process of bereavementCognition: Pts had poor knowledge. Diet and injections major concern. Treatment with medication regarded as failure. Pts taking (more) medication perceived their diabetes to be more serious and less controllable. 